\section{Science Research Council}

THE appointment of Professor B. H. Flowers as Secretary of the Science Research Council, in succession to Sir Harry Melville, has now been confirmed (see Nature, 213, 3; 1967). Professor Flowers has been given leave of absence for five years from his post as head of the Physics Department at the University of Manchester. He says that he intends to return to research at the end of his tenure of office. He will remain chairman of the Computer Board.

\section{Continental Drift}

To celebrate its elevation to the status of a university college, Chelsea College of Science and Technology has inaugurated a yearly special lecture, to be called the Chelsea Lecture. The first was given on February 7 by Professor P. M. S. Blackett, on the subject of Continental Drift.

Suspicions about continental drift were not new, said Professor Blackett, but there were now many pieces of evidence which, taken together, made the theory absolutely convincing. The presence of corals, salt and fossils in regions in which they could not possibly have originated all showed a similar trend of movement. Glaciation over large areas of Africa, India, South America and Australia could only have occurred if they had once been much closer together; there was not enough water in the world to make an ice-cap large enough to cover them in their present geographical positions. Rock magnetism had proved a powerful tool, and classic studies of faults such as the Great Glen in Scotland, the San Andreas Fault in California, and the Great New Zealand Fault had shown that relative movement between land masses could and did occur. The rate of movement rarely reached $6 \mathrm{~cm} / \mathrm{y}$, and was more usually between 1 and $5 \mathrm{~cm} / \mathrm{y}$. More evidence was supplied by the Mid-Atlantic Ridge, placed equidistant between the coasts of Africa and South America. On the ridge itself, there are active volcanoes, but farther out the volcanoes are older, indicating a movement of material away from the centre.

To provide an explanation, Professor Blackett admitted, was harder; convection currents in the Earth's core, and much slower currents in the mantle itself, had been proposed. These could explain why sedimentary rocks, laid down on the ocean floor, were sometimes found on the tops of mountains.

\section{Compulsion on Pesticides}

THE existing voluntary system for controlling the use made of pesticides in Britain will be replaced by a compulsory scheme if the Advisory Committee on Pesticides and Other Toxic Chemicals has its way. In a report now published (Review of the Present Safety Arrangements for the Use of Toxic Chemicals in Agriculture and Food Storage, H.M.S.O., 6s.), the committee argues that although the voluntary Pesticides Safety Precautions Scheme has been found to "work remarkably well", it cannot be as comprehensive as the circumstances require. The committee points out that, with present arrangements, there can be nothing to prevent a toxic substance being put on the market by a manufacturer not wishing to participate in the voluntary scheme, nothing to restrict the import by potential users of toxic materials, and nothing to ensure that the labels used by manufacturers for marking their materials, on which the effectiveness of the voluntary scheme depends, are as accurate as the considerations of safety would demand. The advisory committee is particularly concerned that the British Government should have powers to act "rapidly and effectively" if the need should arise.

By all accounts, the principal manufacturers of pesticides in Britain now support this conclusion, largely on the grounds that they would prefer to know precisely where they stand. Nevertheless, the introduction of a compulsory scheme would be an important break with the precedents of the recent past. No doubt manufacturers of pharmaceuticals will now be asking themselves whether the existing voluntary arrangements for the approval of drugs under the Dunlop Committee may be replaced by a compulsory system.

On pesticides, the advisory committee recommends that it should be made an offence to sell, supply or import any pesticide product for use in agriculture, gardening or food storage which has not been licensed by the appropriate government department. Pesticides would be tested for mammalian toxicity, carcinogenicity, residue persistence and effects on reproduction and on wild life. It would be for manufacturers applying for a licence to vouch for the safety of their products. The advisory committee considered and rejected the possibility of providing an independent check by government laboratories, largely on the grounds of expense.

\section{Aflatoxin}

Dr. J. McL. Phulp of Unilever Research Laboratories at Colworth House has pointed out that a recent item in Nature (212, 1512; 1966) may have given a false impression of the toxic properties of aflatoxin. Dr. Philp and his colleagues were among the first to show that aflatoxin, produced by a mould called Aspergillus flavus on common foods such as peanuts, maize and rice, was responsible for death in turkeys, and gave rise to liver cancer in rats. It is now known that aflatoxin produces liver damage in many animals, including pigs, cows, rats, monkeys and turkeys. In some cases it has been shown to produce liver cancer, but it is not justifiable to suggest that it produces liver cancer in all those animals for which it produces liver damage. In man, aflatoxin has not so far been implicated either as a source of liver damage or of liver cancer, although the possibility cannot be excluded.

\section{Zinc for Healing}

IT appears that zine deficiency may be very common in human beings. According to the U.S. Department of Agriculture, more than half of the states have zinc deficient soils. Although zinc deficiency has been found widely among domestic animals, there has not so far been much evidence of a specific effect of zinc deficiency in man. An article in the Lancet (i, 121; 